Article

\title{
Are (All) Consumers Averse to Bitter Taste?
}

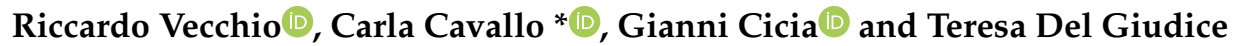 \\ Department of Agricultural Sciences, Università degli Studi di Napoli Federico II, 80055 Portici, Italy; \\ riccardo.vecchio@unina.it (R.V.); cicia@unina.it (G.C.); agriqual@unina.it (T.D.G.) \\ * Correspondence: carla.cavallo@unina.it
}

Received: 10 January 2019; Accepted: 31 January 2019; Published: 2 February 2019

\begin{abstract}
The current study combined hedonic liking with non-hypothetical experimental auctions to measure consumer preferences for bitter tasting food and identify individual socio-demographic and psychographic characteristics that influence bitter aversion. Furthermore, the research analyzed whether consumer preferences for bitter food were influenced by sensory and health-related information. Findings reveal that respondents $(N=205)$ are not averse to bitter taste; while, socio-demographic traits influence bitter acceptance, as higher education level and gender (female) positively affect preferences, together with specific individual characteristics as high compensatory health beliefs. Moreover, results prove that participants positively respond to health-related information, whereas information on bitterness-taste generates lower preferences.
\end{abstract}

Keywords: hedonic liking; experimental auctions; willingness to pay; broccoli pesto

\section{Introduction}

Antioxidants represent a fundamental category of healthy substances that are able to prevent many metabolic diseases [1,2]. These compounds, very often, give the food a bitter taste [3]. This is the case of vegetables from the Brassicaceae family containing glucosinolate hydrolysis products, sulforaphane and indole-3-carbinol [4]. Their effect on the prevention of several types of diseases seems to be substantial and more powerful than general fruit and vegetable consumption $[4,5]$.

Plants produce toxic substances that tend to be bitter as a defense strategy from herbivores [6]. This is the reason why during evolution humans learnt to avoid this sensory property in food as it was a danger signal $[3,7]$. There are several bitter substances that deviate from this bitter-poison link, such as peptides in meat and cheese with multifold effects on human nutrition. The interest of this article is devoted to peculiar bitter substances with healthy properties that are present in Cruciferae (glucosinates) [8]. Bitterness also characterizes other healthy substances in other foods, as: EVOO [9]; saffron [10]; whole wheat bread [11] and tea [12].

In particular, the bitter taste of antioxidants compounds is addressed as being the main cause of rejection of Cruciferae by consumers $[13,14]$. This is leading the food industry and breeders to lower the content of bitter, and thus healthy, substances from these products $[3,15]$. At the same time, since exposure is one of the main powerful elements in lowering the avoidance toward bitter taste [16], bitter taste is also constantly dropping its popularity among consumers $[17,18]$.

Nevertheless, there can be some exceptions to this general tendency which can be represented by individual differences among consumers. In fact, the level of bitterness detected by humans in food has a source of variability that is genetically determined [19]. This trait is believed also to be an indicator of overall taste sensitivity and it is supposed to influence consumers' perceptions and preferences and, in turn, to influence their diet $[19,20]$.

Other deviations from bitterness rejection can occur when consumers attach a positive meaning to the bitterness feature. For example, in products such as chocolate, coffee or alcoholic beverages, 
due to the goals that are connected to their consumption, the consumer overcomes innate rejection and appreciates the presence of the bitter taste [21-24], reaching the point that a preference for bitterness becomes mainstream for such products $[25,26]$.

In this context, the aim of the present research is to investigate consumer preferences for bitter tasting Cruciferae and identify individual socio-demographic and psychographic characteristics influencing bitter avoidance/acceptance. Furthermore, the study analyzes whether consumer preferences for bitter food are influenced by sensory and health-related information. Broccoli pesto was selected as a case study considering that broccoli is among the most consumed vegetables in the geographical area of analysis (Southern Italy) and that pesto is very popular among individuals of different social classes.

\section{Materials and Methods}

Adapting the approach proposed by Combris and colleagues [27], the current study combines features of hedonic tests with those of economic experiments to measure consumer preferences for different food characteristics and the way in which sensory and health information influence these preferences. Non-hypothetical experimental auctions were used to elicit individual preferences (recording monetary values) in order to avoid problems related to hypothetical bias [28], while hedonic ratings were applied to measure the respondent's blind and expected liking. Experimental auctions use real products and real money and are designed to induce each participant to submit a bid that sincerely reflects her/his value for one unit of the auctioned goods [29]. Therefore, experimental auctions mimic a real market scenario, allowing researchers to determine the monetary value people place on specific goods. However, from the perspective of a research participant, the experimental auction procedure presents individuals with the unfamiliar problem of being asked to provide the highest price that they would be willing to pay for one or more (often novel) goods [30]. Consequently, experimental auctions are anticipated by training rounds in which the participants are shown, in a very easy way, the simple task that they are required to perform.

\subsection{Stimuli}

In order to understand the product to be used as a case study for the current analysis, four focus groups $(N=38)$ were conducted with consumers of different age categories (ranging from 18 to 64 years old). The focus groups were aimed at investigating the opinions of consumers toward bitter taste in general and toward particular products characterized by this flavor. The discussions were also extended to participants' habits in terms of cooking and eating to uncover potential, privileged targets for the subsequent study. The focus group data analysis suggested that the product that was best fitting with the research objectives was broccoli. Indeed, previous literature has identified vegetables belonging to the family of Cruciferae as a model food for bitterness since, according to consumers, broccoli is, on average, more bitter than other vegetables [31]. Furthermore, agreeing with previous studies, broccoli is the most consumed and appreciated product within the Cruciferae family in Southern Italy [32] where there are also locally grown typical bitter Cruciferae cultivars [33]. In addition, since the exposure of consumers from Southern Italy to this bitter vegetable is medium to high, consumers' avoidance toward this product is expected to be lower compared to other foods [3]. This made Southern Italy a suitable case study, also considering that this place has been the establishing point of the Mediterranean Diet, which contains a large share of vegetables over other food groups [34-36].

Finally, this product is widely recognized by consumers as very healthy, being an important prevention factor against several diseases and other conditions [37]. Previous literature suggested that when healthy goals are very salient in the mind of the consumers, they can be willing to compromise taste for healthiness, leading to another motivation for analyzing preferences for bitterness via a broccoli-based food product [38,39].

Specifically, three experimental products, i.e.; broccoli pesto, were produced for the specific aims of the research by a private food company. The choice of pesto was motivated by the possibility to 
include this food in many dishes without particular cooking knowledge, and because pesto is popular among individuals of different social classes $[40,41]$. The three broccoli pesto were produced by one factory and on the same day, according to the same recipe, only differing in the percentage of broccoli leaves that were contained in the final product, being that leaves are more bitter compared to sprouts (Table 1). This difference leads to diverse bitterness of the goods. Indeed, the three broccoli pesto were evaluated by a professional sensory panel assigning a level of bitterness to each on a scale from 1 (extremely low) to 9 (extremely high), respectively of 1 (hereafter called LOW), 4 (hereafter called MEDIUM) and 7 (hereafter called HIGH).

Table 1. Experimental products' features.

\begin{tabular}{cccc}
\hline Product & Coding & Ingredients & Bitterness Level \\
\hline 100 gram jar of broccoli & LOW & $\begin{array}{c}95 \% \text { broccoli (75\% sprouts, 25\% leaves), 4.5\% extra } \\
\text { virgin olive oil, salt, white wine vinegar and lactic acid. }\end{array}$ & 1 \\
$\begin{array}{c}\text { pesto \#1 } \\
100 \text { gram jar of broccoli } \\
\text { pesto \#2 }\end{array}$ MEDIUM & $\begin{array}{c}95 \% \text { broccoli (50\% sprouts, 50\% leaves), 4.5\% extra } \\
\text { virgin olive oil, salt, white wine vinegar and lactic acid. } \\
\text { 100 gram jar of broccoli } \\
\text { pesto \#3 }\end{array}$ HIGH & $\begin{array}{c}95 \% \text { broccoli (25\% sprouts, 75\% leaves), 4.5\% extra } \\
\text { virgin olive oil, salt, white wine vinegar and lactic acid. }\end{array}$ & 4 \\
\hline
\end{tabular}

\subsection{Experimental Procedure}

The experimental auctions protocol was developed following well-established guidelines [29,42]. In particular, the random $n$th price auction [43] with the full-bidding approach was applied. In this procedure, the core features of the Becker-DeGroot-Marschak (BDM) mechanismmechanism and second price auction are combined, obtaining an endogenous price of the market (as in a second price auction), however it is determined in a random way (like the in the BDM mechanism). Specifically, all bidders simultaneously submit sealed bids for all the auctioned goods, then each bid is rank-ordered from highest to lowest; a random number is subsequently drawn between 2 and the number of participants in the experimental session (the $n$ ), then finally, one unit of the good is sold to each of the $(n-1)$ highest bidders at the $n$ th-price [43]. As noted by Shogren and colleagues [43] randomness is used to effectively engage all bidders, providing all participants a positive probability of being a purchaser of the auctioned good. This type of auction was selected as it allows all bids to influence the results of the auction and thus also effectively engages participants with lower interest towards the goods as even low bids could become binding and thereby lead to a large percentage of participants purchasing the auctioned products. This mechanism is incentive compatible, meaning that subjects have an incentive to truthfully reveal their value for all the auctioned products [44]. Among the core advantages of experimental auctions over other incentive-compatible value elicitation methods, we should highlight that the auctions deliver willingness-to-pay (WTP) for each individual participant, avoiding the need to make parametric assumptions about the shape of the market demand curve [45], and also grants participants maximum freedom compared to other mechanisms in which participants can only accept/reject the price of a product described as a bundle of attributes [46].

In the current study, a hybrid within-subject and between-subject design was implemented, i.e. all participants $(N=205)$ performed the same tasks and received the same information in round 1 (blind round), whereas in Round 2 (expected round), half the sample was provided with an information treatment on the bitterness level of the products (i.e. sensory) and half the sample received information on the health properties of the goods (Figure 1). A total of 18 experimental sessions were performed on six consecutive weekdays and throughout the morning and afternoon hours, with $10 \pm 2$ participants each, lasting approximately 65 minutes. Individuals were compensated for their time with $20 €$ cash. The entire experimental flow involved seven consecutive steps: (1) participants were welcomed into the experimental laboratory, were asked not to communicate with each other and to complete the informed consent and received the participation fee; (2) the procedure of computerized sealed-bid random $n$th experimental auction was fully explained and training rounds with chocolate bars were performed; (3) participants blind tasted the three products one by one and expressed their overall 
liking on a 9-point hedonic scale [47] and WTP for a 100 gram jar; (4) participants were randomly assigned to one of the two experimental conditions: healthiness or bitterness information treatments and expressed their expected liking (9-point hedonic scale) and WTP for the same three products; (5) post-auction survey (drawn on previous food consumer research and economic theory); (6) one round of auctions, one product and one price were randomly drawn by a participant, the products were then sold to the winners (to avoid demand reduction effects). The post-auction questionnaire and the tasting procedure were pretested with a small group of consumers $(n=12)$ to avoid ambiguity and effects from the information treatments' wording. All procedures that were performed in the studies involving human participants were in accordance with the ethical standards of the institutional and/or national research committee and with the 1964 Helsinki declaration and its later amendments or comparable ethical standards. Informed consent was obtained from all individual participants that were included in the study.

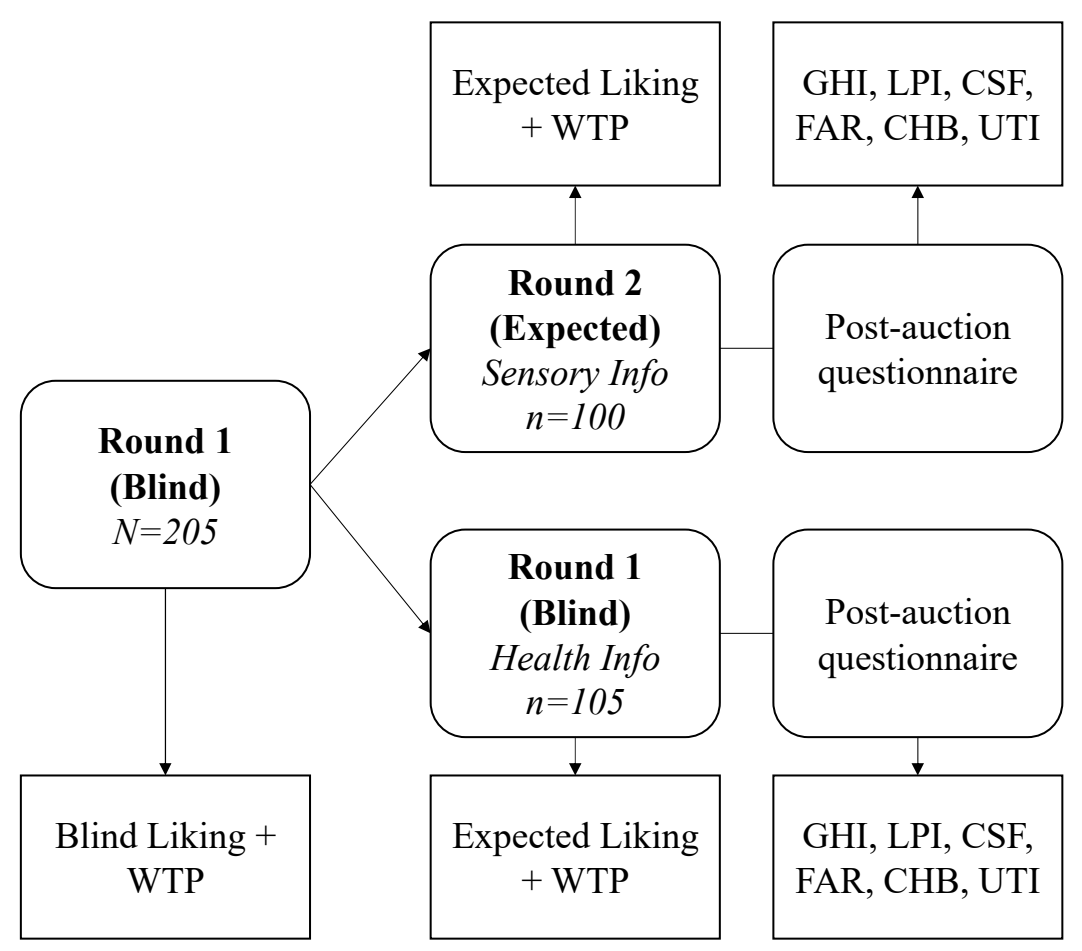

Figure 1. Experimental design. WTP (willingness-to-pay), GHI (General Health Interest), LPI (Light Product Interest), CSF (Craving for Sweet Foods), FAR (Food as A Reward), CHB (Compensatory Health Beliefs), UTI (Unhealthy=Tasty Intuition).

\subsection{The Survey}

From an analysis of literature, we developed a set of socio-demographic characteristics of consumers that was supposed to be able to influence perception and liking of bitter products. According to that, the post-auction survey was structured.

We started from general questions about purchase and consumption habits of consumers in order to understand their familiarity and involvement with vegetables as a product $[48,49]$. Then, we asked respondents about their current level of hunger, as some motivational states are believed to affect food preferences [50].

Since, in the case of the investigated products, we have a gap between taste and healthiness, we used scales that were developed to understand to what extent the respondents are willing to trade taste for health benefits in the food that they usually eat. The seven scales are: General Health Interest (GHI), Light Product Interest (LPI), Natural Product Interest (NPI). Craving for sweet foods (CSF), Food as a reward (FAR), Compensatory Health Beliefs (CHB), Unhealthy=Tasty Intuition (UTI). Specifically, 
the Health and Taste Attitude Scales (composed of three sub-scales [51]) are directed at measuring the importance that is attached to sensory and health aspects in food choice. On the other hand, the Unhealthy=Tasty Intuition [39] is able to understand to what extent these two aspects are considered antithetical. Besides, Compensatory Health Belief (CHB, [52]) is the scale that measures how the respondent is indulgent in the case of unhealthy behaviors.

Nevertheless, we considered a physiological difference among humans: individuals have different levels of taste sensitivity that are genetically determined, and this is especially true for bitter taste [19]. This difference leads consumers to eat more or less bitter foods, so it is able to shape either the individuals' diets and their bitterness exposure. Exposure, in turn, can shape bitterness liking. So, understanding the taste sensitivity can help to disclose important antecedents to bitterness acceptance. To this purpose, we measured taste sensitivity of participants through the tasting of a solution made with 6-n-propyl-thiouracil (PROP) at the end of the experiment. This solution is plain, slightly bitter or extremely bitter according to the personal level of taste sensitivity, so we asked participants to rate the bitterness of this solution on a scale from 1 to 9 . At this point, it was possible to categorize consumers in the subsequent groups: non-tasters (rating from 1 to 3), medium tasters (rating from 4 to 6) and super-tasters (rating from 7 to 9). At the end, general demographics (age, gender, living area, etc.) closed the questionnaire.

\subsection{Information Treatments}

In the blind tasting round (Round 1), the products were offered to individuals one at a time on a white plastic spoon containing 4 grams of product and, for each participant, a package of unsalted crackers was placed on a small paper plate together with a bottle of still spring water. The order of samples was randomized across sessions according to a Latin square that was balanced for order and first-order carry-over effects [53]. Participants were also asked to rinse their palate with still water and eat a cracker for neutralization between tasting different samples. To increase realism, pesto jars were handed out to participants before collecting the bids. To prevent the influence of brand, such as packaging and other external cues, the three jars were provided with a label containing only the legally required information (Figure 2).

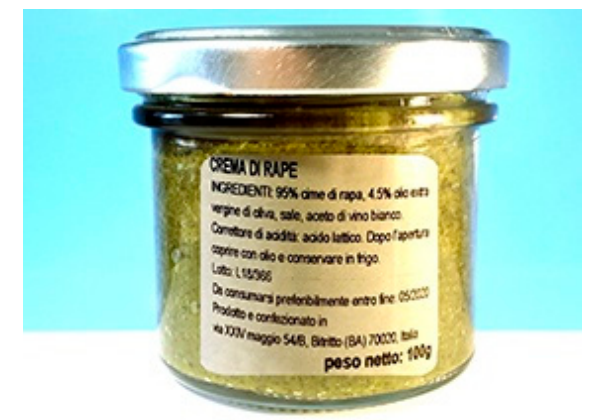

Figure 2. Auctioned Broccoli pesto jar. Note: Beyond the ingredient list (top), the label reported the best before consumption date, producer's address and net weight (bottom).

In the second round (expected liking), two types of information were distributed via personal monitors and read aloud by one researcher. Specifically, 100 participants received sensory information on the level of bitterness of each jar of pesto: low, medium and high (sensory information treatment), while 105 participants received information on the amount of polyphenols content of each good (low, medium and high) and the relation between polyphenols and personal health (health information treatment). Randomization of participants to the information treatments was successful as all socio-demographic characteristics are balanced over the subgroups, according to statistical analysis. 


\subsection{Sample Characteristics}

A central location test was performed in Naples (Southern Italy) where 205 participants were recruited by a non-profit association according to two eligibility criteria: consumers of vegetables and at least partially responsible for the family's grocery shopping. In addition, participants were asked not to smoke, eat or drink anything, except water, at least 1 hour before their participation in the experiment to avoid any influence of their taste perception from prior smoke/food/beverage consumption. Participants signed an informed consent prior to their participation. In terms of demographic data, $76 \%$ of respondents lived in an urban area, the mean age was 34.2 years old (SD 13.4), 63\% were females, the average number of household members was 3.6 and their income was in line with the national average (the lower interval was less than $2.400 €$, the middle interval was between $2.400 €$ and $3.400 €$ and the upper interval was more than $3.400 €$ intervals were selected considering the national average provided by ISTAT [54]). Most of respondents are within a normal weight, are not on a diet and are not hungry at the moment of the experiment (Table 2). Moreover, the majority of participants have a high taste sensitivity which was measured through the PROP test.

Table 2. Characteristics of participants.

\begin{tabular}{|c|c|}
\hline Variable & $n$ \\
\hline \multicolumn{2}{|l|}{ Age } \\
\hline$<25$ & 60 \\
\hline $25-34$ & 81 \\
\hline $35-44$ & 17 \\
\hline $45-54$ & 19 \\
\hline $55-64$ & 25 \\
\hline$>64$ & 3 \\
\hline \multicolumn{2}{|l|}{ Gender } \\
\hline Female & 130 \\
\hline Male & 75 \\
\hline \multicolumn{2}{|l|}{ Education } \\
\hline High school diploma or lower & 78 \\
\hline Degree & 105 \\
\hline Post-degree & 22 \\
\hline \multicolumn{2}{|l|}{ Body Mass Index (BMI) } \\
\hline Underweight & 5 \\
\hline Normal weight & 141 \\
\hline Overweight & 42 \\
\hline Obese & 17 \\
\hline \multicolumn{2}{|l|}{ Currently on a diet } \\
\hline No & 172 \\
\hline Yes & 33 \\
\hline \multicolumn{2}{|l|}{ Financial situation } \\
\hline Worse than the national average & 16 \\
\hline In line with the national average & 163 \\
\hline Better than the national average & 26 \\
\hline \multicolumn{2}{|l|}{ Preferred groceries sale channel } \\
\hline Hyper/supermarket & 51 \\
\hline Small shop & 79 \\
\hline Direct sale & 23 \\
\hline Local Market & 31 \\
\hline Farmers' market & 21 \\
\hline \multicolumn{2}{|c|}{ Level of hunger at the time of the experiment } \\
\hline Low & 109 \\
\hline Medium & 66 \\
\hline High & 30 \\
\hline
\end{tabular}


Table 2. Cont.

\begin{tabular}{cc}
\hline Variable & $\boldsymbol{n}$ \\
\hline Taste Sensitivity (PROP test) & \\
Non-tasters & 21 \\
Medium tasters & 25 \\
Super-tasters & 159 \\
\hline
\end{tabular}

In addition, individual psychographic traits were recorded to further investigate the consumers' heterogeneity (reported in Table 3). On average, participants declare to be medium-to-highly interested in personal health (4.85 mean score out of 7 for General Health Interest), they are moderately appealed by light products (3.8 out of 7 for Light Products Interest), reasonably interested in natural products (4.42 out of 7 for Natural Products Interest), highly appealed to sweet foods (5.4 out of 7 for Craving for sweet foods) and have a medium-to-high tendency to use food as a reward (4.47 out of 7 for Food as a reward). Furthermore, the sample is, on average, not convinced by trade-offs between healthy and unhealthy habits ( 2.57 out of 7 for Compensatory Health Beliefs) and by the intuition that what is tasty is always unhealthy (2.85 out of 7 for Unhealthy=Tasty Intuition).

Table 3. Participants' psychographic characteristics.

\begin{tabular}{lll}
\hline & Mean & St. Dev. \\
\hline General Health Interest (GHI) & 4.85 & 1.06 \\
Light Product Interest (LPI) & 3.80 & 1.17 \\
Natural Product Interest (NPI) & 4.42 & 1.03 \\
Craving for sweet foods (CSF) & 5.40 & 1.20 \\
Food as a reward (FAR) & 4.47 & 1.39 \\
Compensatory Health Beliefs (CHB) & 2.57 & 0.71 \\
Unhealthy=Tasty Intuition (UTI) & 2.85 & 1.54 \\
\hline \multicolumn{2}{c}{ Note: All scales range from 1 (low) to 7 (high). }
\end{tabular}

\subsection{Data Analysis}

To formally test whether the WTP for the three products were different during the first blind round, we conducted a series of complementary statistical tests on the equality of means, samples distribution and the equality of distributions. For the auction data, we followed the common practice that was used in similar studies and estimated a Tobit model censored at zero [29]. To increase the power of the statistical tests with the econometric model, we pooled the observations on WTP across the three products. Hence, the sample size for this fitted model was $615(205 \times 3)$. Specifically, to identify the factors that influenced WTP, we estimated a Tobit model where $\mathrm{WTP}_{j i}$ is the latent value of WTP for broccoli pesto type $j$ and subject $i$, expressed as a function of pesto type and individual characteristics, and the individual specific disturbance term for subject $i$ is $\mathrm{u}_{i}$. The final model is:

$\mathrm{WTP}_{j i}=\beta_{0}+\beta_{2}$ Pesto $_{j}+\beta_{3}$ age $+\beta_{4}$ female $+\beta_{5} \mathrm{BMI}+\beta_{6}$ education $+\beta_{7}$ financial situation $+\beta_{8}$ market purchaser $+\beta_{9}$ hunger $+\beta_{10}$ super-taster $+\beta_{11}$ hedonic liking score $+\beta_{12}$ LPI $+\beta_{13}$ CSF $+\beta_{14}$ $\mathrm{FAR}+\beta_{15} \mathrm{CHB}+\beta_{16} \mathrm{UTI}+\beta_{17} \mathrm{GHI}+\beta_{18} \mathrm{NPI}+\mathrm{u}_{i}$.

All data analyses were carried out using STATA 15.

\section{Results}

\subsection{Bitter Preferences and Drivers in Blind Liking Round (Round 1)}

Mean hedonic scores and WTP that were expressed for the three products in the blind round suggest that consumers equally liked the products as no statistically significant differences among the three pesto are detected (Figure 3). 


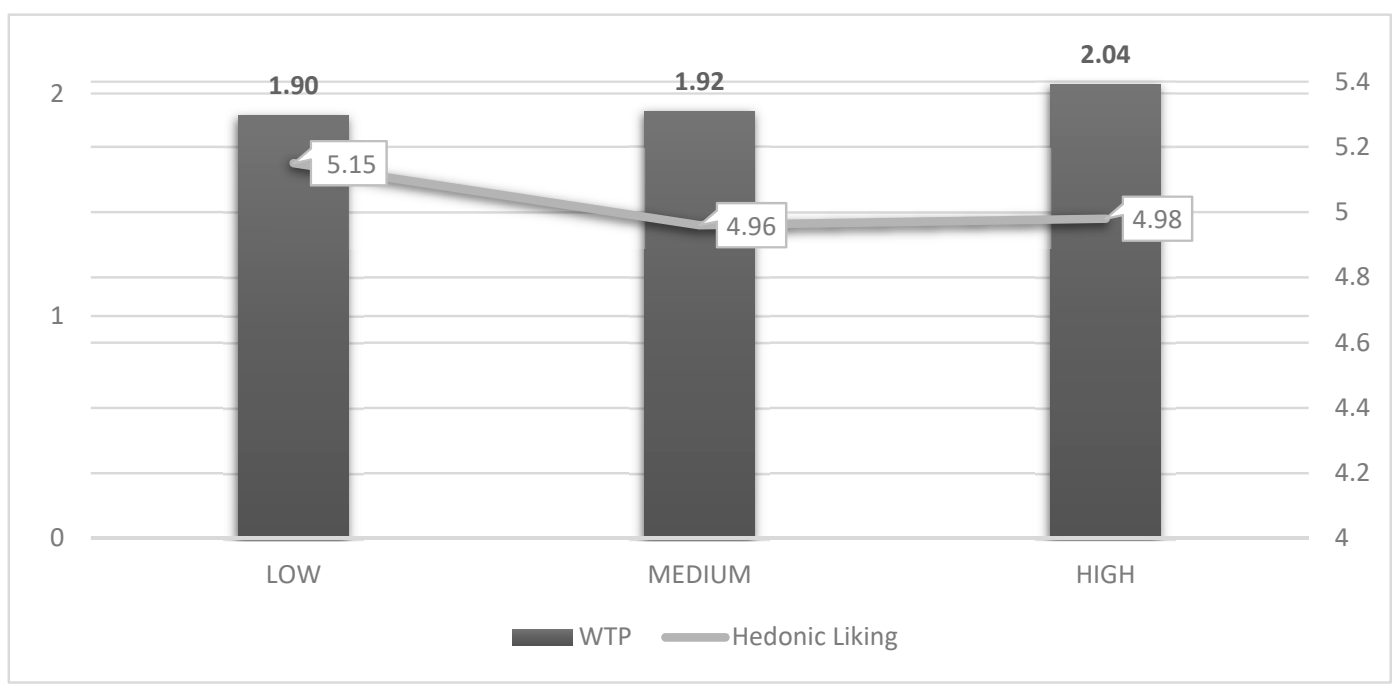

Figure 3. Blind round, mean WTP (€) and hedonic liking scores.

Data from the first round were further analyzed through a Tobit model in order to understand which consumer characteristics are able to characterize the different WTP. Table 4 reports the estimated coefficients (and standard errors in brackets). The analysis was performed stepwise, thus the effect of each variable was tested and, in the end, only statistically significant relations were kept in the final explanatory model. Hence, a smaller set of variables is present in the model compared to the ones that were collected with the experiment and the questionnaire.

Table 4. Selected parameter's estimates of the Tobit model for WTP collected during the blind round (Round 1).

\begin{tabular}{|c|c|}
\hline Variable & Coefficient \\
\hline \multicolumn{2}{|c|}{ Auctioned products (reference category: Low) } \\
\hline MEDIUM & $\begin{array}{l}0.09 \\
(0.11)\end{array}$ \\
\hline $\mathrm{HIGH}$ & $\begin{array}{l}0.21 \text { * } \\
(0.10)\end{array}$ \\
\hline \multicolumn{2}{|l|}{ Socio-demographics } \\
\hline Male & $\begin{array}{l}-0.26^{* * *} \\
(0.09)\end{array}$ \\
\hline Education & $\begin{array}{l}0.11 \text { ** } \\
(0.04) \\
\end{array}$ \\
\hline \multicolumn{2}{|l|}{ Individual characteristics } \\
\hline Local market purchaser & $\begin{array}{l}-0.24 \text { * } \\
(0.13)\end{array}$ \\
\hline Level of hunger & $\begin{array}{l}0.09^{*} \\
(0.04)\end{array}$ \\
\hline Super-taster & $\begin{array}{l}0.05^{* *} \\
(0.02)\end{array}$ \\
\hline Hedonic Liking Score & $\begin{array}{l}0.29^{* * *} \\
(0.03)\end{array}$ \\
\hline Light Product Interest (LPI) & $\begin{array}{l}0.13^{* * *} \\
(0.04)\end{array}$ \\
\hline Craving for sweet food (CSF) & $\begin{array}{l}-0.11^{* * *} \\
(0.04)\end{array}$ \\
\hline
\end{tabular}


Table 4. Cont.

\begin{tabular}{ll}
\hline Variable & Coefficient \\
\hline Food as a reward (FAR) & $0.06^{*}$ \\
& $(0.03)$ \\
\hline \multirow{2}{*}{ Compensatory Health Beliefs (CHB) } & $0.21^{* * *}$ \\
& $(0.05)$ \\
\hline \multirow{2}{*}{ Unhealthy=Tasty Intuition (UTI) } & $-0.07^{* *}$ \\
\hline \multirow{2}{*}{ Constant } & $(0.03)$ \\
\hline
\end{tabular}

Note: Asterisks represent statistically significant coefficients at the levels: ${ }^{*} p \leq 0.1 ;{ }^{* *} p \leq 0.05 ;{ }^{* * *} p \leq 0.01$.

On average, WTP for the HIGH product were higher compared to the other two pesto. A higher WTP was registered for consumers with specific socio-demographic characteristics: individuals with a higher education level and participants who were hungry at the moment of the experiment. Whereas, male respondents expressed lower WTP compared to females. Furthermore, higher WTP were made by super-taster respondents, by individuals that scored high on the Light Product Interest (LPI) scale, on the Food as a reward scale (FAR) and on the Compensatory Health Belief scale (CHB). Not surprisingly, hedonics liking scores also had a positive effect on WTP. Conversely, WTP were negatively influenced by higher scores on the Craving for sweet foods (CSF) scale and by the unhealthy=tasty intuition (UTI) index. Finally, respondents that regularly buy vegetables in local markets expressed lower WTP for the auctioned products.

\subsection{Information Treatment's Effects on Consumer Preferences (Round 2)}

Considering data from the second round's (Expected liking) findings revealed different mean WTP among the two information treatments (Figure 4). In the health information treatments, products communicated as having higher polyphenols (MEDIUM and HIGH) content received statistically higher WTP. While, in the sensory treatment (i.e. information on bitter taste scores are conveyed), the opposite occurs, revealing participants' positive response to health-related information and negative expectations from a bitter-tasting food.

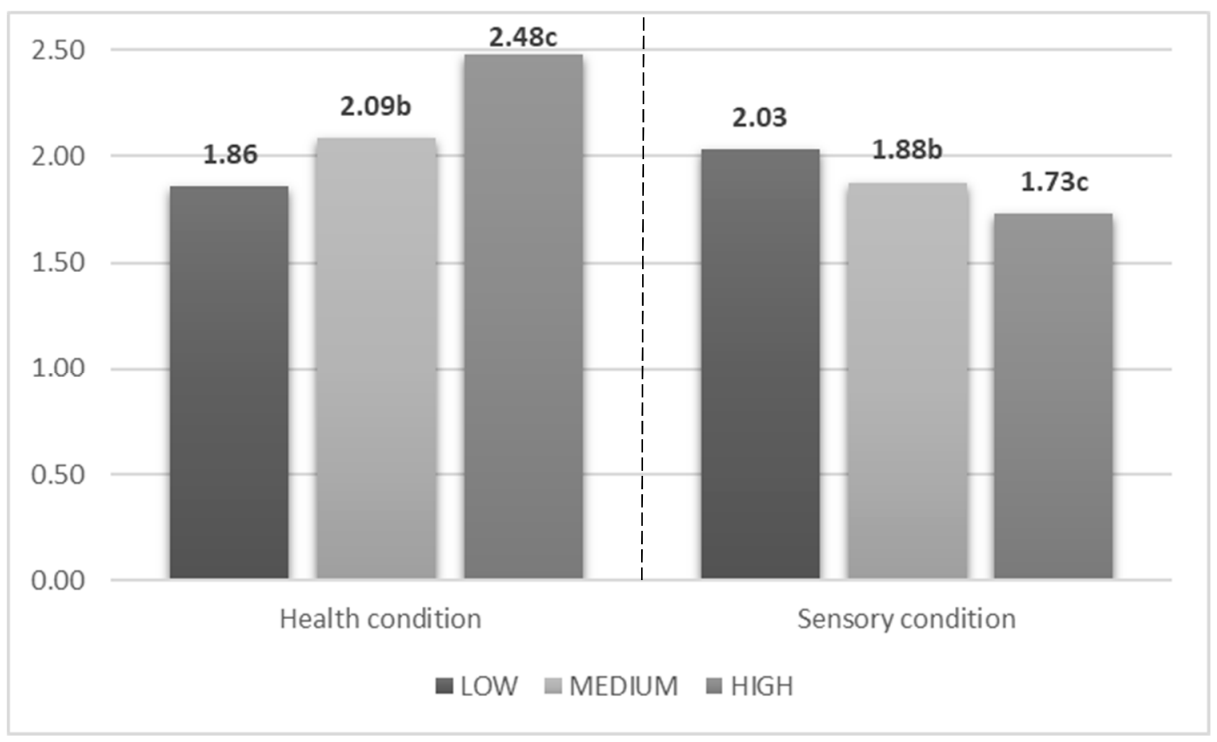

Figure 4. Mean WTP $(€)$ in the Expected round. Note: Mean bids with different superscripts are significantly different according to a Wilcoxon test for paired samples $(p<0.05)$ within the information treatments. 


\section{Discussion}

Consumers' preferences are affected by many factors; even when sensory evaluations reveal high liking scores, extrinsic characteristics can strongly impact final choices. The present study combined hedonic liking with non-hypothetical experimental auctions to measure consumer preferences for bitter tasting food and identify individual socio-demographic and psychographic characteristics related to bitter avoidance/acceptance, also analyzing whether consumer preferences for bitter food are influenced by sensory and health-related information.

Mean WTP reveals that respondents are not averse to bitter taste, as no statistically significant difference was detected in the blind liking scores and in WTP among the three broccoli pesto (Round 1). This result was somewhat unexpected as there is ample literature that demonstrates that, among consumers, there is a wide aversion toward bitter taste [17,55-57]. The previously underlined exceptions were defined for particular foods, such as chocolate or coffee [23,58,59], especially in the presence of specific motivational states [50]. Nevertheless, the explanatory model revealed an additional detail: not only that bitterness was not disliked, however that among the tested products, the most bitter received the higher bids. This confirms that our research disclosed a further exception to the widespread avoidance from consumers toward bitterness in food.

The reasons behind this bitterness acceptance are still unclear. Nevertheless, there is no evidence that bitterness acceptance can be related to the physiology of the sample of respondents. In fact, the wide majority of consumers were identified as supertasters (Table 2); furthermore, the explanatory model showed that, on average, supertasters' bids were higher than the ones that were expressed by the other groups of participants (Table 4). Besides, the sample contained a wide share of young consumers who generally tend to be averse to bitter taste [60]. There is room to suppose that reasons rely on socio-cultural factors. In our study, some socio-demographic traits are related to bitterness acceptance, for example, higher education level and gender (female) characterize respondents who showed preference for bitter products, together with specific individual characteristics, such as high compensatory health beliefs.

The element that led consumers to increase their bids for more bitter products may be the healthiness of the investigated products. In fact, characteristics of consumers that were collected with the questionnaire showed that the tested sample was made, on average, by respondents who were tendentially concerned for their health, fond of natural food and who were convinced that healthy food tastes better (Table 3).

The hypothesis that healthiness plays a pivotal role in judgements of consumers can be further confirmed by the second part of the research. In fact, results from round 2 of the experiment (Expected liking) proved that participants positively responded to health-related information (increasing WTP and liking score), while information on bitterness generates lower preferences. This result is in line with previous research; in fact, literature suggests that consumers use the word bitter with a negative meaning, preferring synonyms in positive contexts [61], therefore, the tested sensory message generated negative expectations in consumers. Meanwhile, the effectiveness of health-related messages in generating positive expectations has already been shown in previous studies [62-64]. Especially when healthy goals are very salient in the mind of consumers, they can be willing to compromise taste for healthiness $[38,39]$. This finding has been reinforced in our study by the estimation of a model which yielded that consumers, after a healthy framing, did raise their WTP in a significant way only for the most bitter product (HIGH).

A possible explanation for consumers lowering their WTP within the taste message framing can be found in selective attention [65], as consumers do not like bitterness and use the word bitter with a negative meaning, so the message about bitterness can lead them to concentrate on such a feature and lower their ratings. Moreover, current results demonstrate the importance of attaching positive information to products with a low / poor image (i.e. broccoli), as information affects taste beliefs and, in turn, has a large impact on selection behavior [66]. This result could yield practicable suggestions for promotion strategies that are aimed at increasing the popularity for bitter tasting products. In fact, 
we believe that salient information about health can also contribute to generate positive expectations in healthy products that are not preferred by the majority of the population. Due to the effect of exposure, consumers can get accustomed to the taste and learn to appreciate it, just as what happened in the case of bitter chocolate [59].

Limitations of the current study lie in the narrow area of research with homogenous food traditions and the focus on one specific product (broccoli pesto), while a national or cross-national study performed on multiple foods would provide a broader view of preferences of consumers toward bitter taste, not being strictly linked to the features of the case study product. Then, a research conducted on a sample that better represents the age distribution of the population would yield more detailed results about the reaction of consumers belonging to different age groups. Furthermore, the present study investigated only two types of information treatments (health and sensory info), whereas different messages as well as non-traditional framings, such as nudging-based techniques, could be employed and tested.

Author Contributions: Conceptualization, R.V., C.C., G.C. and T.D.G.; methodology, R.V., G.C. and T.D.G.; formal analysis, C.C. and R.V.; data curation, C.C. and R.V.; writing-original draft preparation, C.C. and R.V.; writing-review and editing, R.V., C.C., G.C. and T.D.G.; supervision R.V., G.C. and T.D.G.

Funding: This research was funded by COMPAGNIA DI SAN PAOLO.

Acknowledgments: This research was carried out in the frame of Programme STAR and was financially supported by the University of Naples Federico II and Compagnia di San Paolo. BEHAVE Project.

Conflicts of Interest: The authors declare no conflict of interest. The funders had no role in the design of the study; in the collection, analyses, or interpretation of the data; in the writing of the manuscript, or in the decision to publish the results.

\section{References}

1. Shahidi, F.; Ambigaipalan, P. Phenolics and polyphenolics in foods, beverages and spices: Antioxidant activity and health effects-A review. J. Funct. Foods 2015, 18, 820-897. [CrossRef]

2. Williamson, G.; Manach, C. Bioavailability and bioefficacy of polyphenols in humans. II. Review of 93 intervention studies. Am. J. Clin. Nutr. 2005, 81, S243-S255. [CrossRef] [PubMed]

3. Drewnowski, A.; Gomez-Carneros, C. Bitter taste, phytonutrients, and the consumer: A review. Am.J. Clin. Nutr. 2000, 72, 1424-1435. [CrossRef] [PubMed]

4. Keck, A.-S.; Finley, J.W. Cruciferous vegetables: Cancer protective mechanisms of glucosinolate hydrolysis products and selenium. Integr. Cancer Ther. 2004, 3, 5-12. [CrossRef] [PubMed]

5. Verhoeven, D.T.; Goldbohm, R.A.; van Poppel, G.; Verhagen, H.; van den Brandt, P.A. Epidemiological studies on brassica vegetables and cancer risk. Cancer Epidemiol. Prev. Biomark. 1996, 5, 733-748.

6. Laycock, W. Coevolution of poisonous plants and large herbivores on rangelands. J. Range Manag. 1978, 335-342. [CrossRef]

7. Del Giudice, T.; Cavallo, C.; Vecchio, R. Credence attributes, consumers trust and sensory expectations in modern food market: Is there a need to redefine their role? Int. J. Food Syst. Dyn. 2018, in press.

8. Pernice, R.; Vitaglione, P.; Sacchi, R.; Fogliano, V. Phytochemicals in mediterranean diet: The interaction between tomato and olive oil bioactive compounds. Handb. Food Prod. Manuf. Health Meat Milk Poult. Seafood Veg. 2007, 2, 55.

9. Vitaglione, P.; Savarese, M.; Paduano, A.; Scalfi, L.; Fogliano, V.; Sacchi, R. Healthy virgin olive oil: A matter of bitterness. Crit. Rev. Food Sci. Nutr. 2013, 55, 1808-1818. [CrossRef]

10. Shahi, T.; Assadpour, E.; Jafari, S.M. Main chemical compounds and pharmacological activities of stigmas and tepals of 'red gold' saffron. Trends Food Sci. Technol. 2016, 58, 69-78. [CrossRef]

11. Bakke, A.; Vickers, Z. Consumer liking of refined and whole wheat breads. J. Food Sci. 2007, 72, S473-S480. [CrossRef] [PubMed]

12. Cho, H.Y.; Chung, S.J.; Kim, H.S.; Kim, K.O. Effect of sensory characteristics and non-sensory factors on consumer liking of various canned tea products. J. Food Sci. 2005, 70, S532-S538. [CrossRef]

13. Bravo, L. Polyphenols: Chemistry, dietary sources, metabolism, and nutritional significance. Nutr. Rev. 1998, 56, 317-333. [CrossRef] 
14. Cornelis, M.C.; Tordoff, M.G.; El-Sohemy, A.; van Dam, R.M. Recalled taste intensity, liking and habitual intake of commonly consumed foods. Appetite 2017, 109, 182-189. [CrossRef] [PubMed]

15. Bao, Y.; Fenwick, R. Future perspectives in phytochemical and health research. In Phytochemicals in Health and Disease; CRC Press: Boca Raton, FL, USA, 2004; pp. 311-321.

16. Sorokowska, A.; Pellegrino, R.; Butovskaya, M.; Marczak, M.; Niemczyk, A.; Huanca, T.; Sorokowski, P. Dietary customs and food availability shape the preferences for basic tastes: A cross-cultural study among Polish, Tsimane' and Hadza societies. Appetite 2017, 116, 291-296. [CrossRef] [PubMed]

17. Vabø, M.; Hansen, H. The relationship between food preferences and food choice: A theoretical discussion. Int. J. Bus. Soc. Sci. 2014, 5, 145-157.

18. Cavallo, C.; Caracciolo, F.; Cicia, G.; Del Giudice, T. Extra-virgin olive oil: Are consumers provided with the sensory quality they want? A hedonic price model with sensory attributes. J. Sci. Food Agric. 2018, 98, 1591-1598. [CrossRef]

19. Tepper, B.J. Nutritional implications of genetic taste variation: The role of PROP sensitivity and other taste phenotypes. Annu. Rev. Nutr. 2008, 28, 367-388. [CrossRef]

20. Roselli, L.; Cicia, G.; Cavallo, C.; Del Giudice, T.; Carlucci, D.; Clodoveo, M.L.; De Gennaro, B.C. Consumers' willingness to buy innovative traditional food products: The case of extra-virgin olive oil extracted by ultrasound. Food Res. Int. 2018, 108, 482-490. [CrossRef]

21. Donadini, G.; Fumi, M.D.; Lambri, M. The hedonic response to chocolate and beverage pairing: A preliminary study. Food Res. Int. 2012, 48, 703-711. [CrossRef]

22. Harwood, M.L.; Ziegler, G.R.; Hayes, J.E. Rejection thresholds in chocolate milk: Evidence for segmentation. Food Qual. Prefer. 2012, 26, 128-133. [CrossRef] [PubMed]

23. Masi, C.; Dinnella, C.; Pirastu, N.; Prescott, J.; Monteleone, E. Caffeine metabolism rate influences coffee perception, preferences and intake. Food Qual. Prefer. 2016, 53, 97-104. [CrossRef]

24. Varela, P.; Beltrán, J.; Fiszman, S. An alternative way to uncover drivers of coffee liking: Preference mapping based on consumers' preference ranking and open comments. Food Qual. Prefer. 2014, 32, 152-159. [CrossRef]

25. Geel, L.; Kinnear, M.; De Kock, H. Relating consumer preferences to sensory attributes of instant coffee. Food Qual. Prefer. 2005, 16, 237-244. [CrossRef]

26. Hemmerling, S.; Spiller, A. Cross-National Sensory Segments in the Organic Market Based on Stated Preferences for the Five Basic Tastes. J. Food Prod. Mark. 2016, 22, 767-791. [CrossRef]

27. Combris, P.; Bazoche, P.; Giraud-Héraud, E.; Issanchou, S. Food choices: What do we learn from combining sensory and economic experiments? Food Qual. Prefer. 2009, 20, 550-557. [CrossRef]

28. List, J.A.; Gallet, C.A. What experimental protocol influence disparities between actual and hypothetical stated values? Environ. Resour. Econ. 2001, 20, 241-254. [CrossRef]

29. Lusk, J.L.; Shogren, J.F. Experimental Auctions: Methods and Applications in Economic and Marketing Research; Cambridge University Press: Cambridge, UK, 2007.

30. Corrigan, J.R.; Depositario, D.P.T.; Nayga, R.M., Jr.; Wu, X.; Laude, T.P. Comparing open-ended choice experiments and experimental auctions: An application to golden rice. Am. J. Agric. Econ. 2009, 91, 837-853. [CrossRef]

31. Shen, Y.; Kennedy, O.B.; Methven, L. Exploring the effects of genotypical and phenotypical variations in bitter taste sensitivity on perception, liking and intake of brassica vegetables in the UK. Food Qual. Prefer. 2016, 50, 71-81. [CrossRef]

32. Calabrese, N.; Signorella, G.; Bianco, V. Stem chicory and cima di rapa (broccoli raab). Two typical vegetables of Puglia. Italus Hortus (Italy) 2003, 10, 218-222.

33. Fratianni, F.; Cardinale, F.; Cozzolino, A.; Granese, T.; Pepe, S.; Riccardi, R.; Spigno, P.; Coppola, R.; Nazzaro, F. Polyphenol composition and antioxidant activity of two autochthonous Brassicaceae of the Campania region, Southern Italy. Food Nutr. Sci. 2014, 5, 66. [CrossRef]

34. Trichopoulou, A.; Kyrozis, A.; Rossi, M.; Katsoulis, M.; Trichopoulos, D.; La Vecchia, C.; Lagiou, P. Mediterranean diet and cognitive decline over time in an elderly Mediterranean population. Eur. J. Nutr. 2015, 54, 1311-1321. [CrossRef] [PubMed]

35. Bonanno, A.; Bimbo, F.; Castellari, E.; Sckokai, P. Five-a-Day, Fruit and Vegetables Portions, and the Food Environment: The Italian Case. Appl. Econ. Perspect. Policy 2017, 39, 682-709. [CrossRef]

36. Menozzi, D.; Sogari, G.; Mora, C. Explaining vegetable consumption among young adults: An application of the theory of planned behaviour. Nutrients 2015, 7, 7633-7650. [CrossRef] [PubMed] 
37. Vasanthi, H.R.; Mukherjee, S.; Das, D.K. Potential health benefits of broccoli-a chemico-biological overview. Mini Rev. Med. Chem. 2009, 9, 749-759. [CrossRef] [PubMed]

38. Urala, N.; Lähteenmäki, L. Attitudes behind consumers' willingness to use functional foods. Food Qual. Prefer. 2004, 15, 793-803. [CrossRef]

39. Raghunathan, R.; Naylor, R.W.; Hoyer, W.D. The unhealthy= tasty intuition and its effects on taste inferences, enjoyment, and choice of food products. J. Mark. 2006, 70, 170-184. [CrossRef]

40. Bugge, A.B.; Almås, R. Domestic dinner: Representations and practices of a proper meal among young suburban mothers. J. Consum. Cult. 2006, 6, 203-228. [CrossRef]

41. Romani, S.; Dalli, D. Consumption experiences and product meanings: Pasta for young Italian consumers. In Consuming Experience; Routledge: London, UK, 2013; pp. 77-90.

42. Vecchio, R.; Borrello, M. Measuring food preferences through experimental auctions: A review. Food Res. Int. 2018, 116, 1113-1120. [CrossRef]

43. Shogren, J.F.; Margolis, M.; Koo, C.; List, J.A. A random nth-price auction. J. Econ. Behav. Organ. 2001, 46, 409-421. [CrossRef]

44. Lusk, J.L.; Alexander, C.; Rousu, M.C. Designing experimental auctions for marketing research: The effect of values, distributions, and mechanisms on incentives for truthful bidding. Rev. Mark. Sci. 2007, 5. [CrossRef]

45. Lusk, J.L.; Hudson, D. Willingness-to-pay estimates and their relevance to agribusiness decision making. Appl. Econ. Perspect. Policy 2004, 26, 152-169. [CrossRef]

46. Shi, L.; Xie, J.; Gao, Z. The impact of deal-proneness on WTP estimates in incentive-aligned value elicitation methods. Agric. Econ. 2018, 49, 353-362. [CrossRef]

47. Peryam, D.R.; Pilgrim, F.J. Hedonic scale method of measuring food preferences. Food Technol. 1957, 11, 9-14.

48. Lockie, S. Responsibility and agency within alternative food networks: Assembling the "citizen consumer". Agric. Hum. Values 2009, 26, 193-201. [CrossRef]

49. Verbeke, W.; Vackier, I. Profile and effects of consumer involvement in fresh meat. Meat Sci. 2004, 67, 159-168. [CrossRef] [PubMed]

50. Garcia-Burgos, D.; Zamora, M.C. Exploring the hedonic and incentive properties in preferences for bitter foods via self-reports, facial expressions and instrumental behaviours. Food Qual. Prefer. 2015, 39, 73-81. [CrossRef]

51. Roininen, K.; Lähteenmäki, L.; Tuorila, H. Quantification of consumer attitudes to health and hedonic characteristics of foods. Appetite 1999, 33, 71-88. [CrossRef]

52. Knäuper, B.; Rabiau, M.; Cohen, O.; Patriciu, N. Compensatory health beliefs: Scale development and psychometric properties. Psychol. Health 2004, 19, 607-624. [CrossRef]

53. MacFie, H.J.; Bratchell, N.; GREENHOFF, K.; Vallis, L.V. Designs to balance the effect of order of presentation and first-order carry-over effects in hall tests. J. Sens. Stud. 1989, 4, 129-148. [CrossRef]

54. ISTAT. Reddito Netto Delle Famiglie Italiane. 2018. Available online: http://dati.istat.it/Index.aspx? DataSetCode=DCCV_REDNETFAMFONTERED (accessed on 10 November 2018).

55. Beckett, E.L.; Martin, C.; Yates, Z.; Veysey, M.; Duesing, K.; Lucock, M. Bitter taste genetics-the relationship to tasting, liking, consumption and health. Food Funct. 2014, 5, 3040-3054. [CrossRef] [PubMed]

56. Laaksonen, O.; Knaapila, A.; Niva, T.; Deegan, K.C.; Sandell, M. Sensory properties and consumer characteristics contributing to liking of berries. Food Qual. Prefer. 2016, 53, 117-126. [CrossRef]

57. Majchrzak, D.; Lahm, B.; Duerrschmid, K. Conventional and probiotic yogurts differ in sensory properties but not in consumers' preferences. J. Sens. Stud. 2010, 25, 431-446. [CrossRef]

58. Cavallo, C.; Materia, V.C. Insects or not Insects? Dilemmas or Attraction for Young Generations: A Case in Italy. Int. J. Food Syst. Dyn. 2018, 9, 226-239.

59. Harwood, M.L.; Loquasto, J.R.; Roberts, R.F.; Ziegler, G.R.; Hayes, J.E. Explaining tolerance for bitterness in chocolate ice cream using solid chocolate preferences. J. Dairy Sci. 2013, 96, 4938-4944. [CrossRef] [PubMed]

60. Monteleone, E.; Spinelli, S.; Dinnella, C.; Endrizzi, I.; Laureati, M.; Pagliarini, E.; Sinesio, F.; Gasperi, F.; Torri, L.; Aprea, E. Exploring influences on food choice in a large population sample: The Italian Taste project. Food Qual. Prefer. 2017, 59, 123-140. [CrossRef]

61. Lesschaeve, I.; Noble, A.C. Polyphenols: Factors influencing their sensory properties and their effects on food and beverage preferences. Am. J. Clin. Nutr. 2005, 81, S330-S335. [CrossRef] [PubMed]

62. Hung, Y.; Grunert, K.G.; Hoefkens, C.; Hieke, S.; Verbeke, W. Motivation outweighs ability in explaining European consumers' use of health claims. Food Qual. Prefer. 2017, 58, 34-44. [CrossRef] 
63. Aschemann-Witzel, J.; Grunert, K.G. Influence of 'soft'versus 'scientific'health information framing and contradictory information on consumers' health inferences and attitudes towards a food supplement. Food Qual. Prefrt. 2015, 42, 90-99. [CrossRef]

64. Bonanno, A.; Bimbo, F.; Cleary, R.; Castellari, E. Food labels and adult BMI in Italy-An unconditional quantile regression approach. Food Policy 2018, 74, 199-211. [CrossRef]

65. Posner, M.I. Orienting of attention. Q. J. Exp. Psychol. 1980, 32, 3-25. [CrossRef] [PubMed]

66. Bernard, J.C.; Liu, Y. Are beliefs stronger than taste? A field experiment on organic and local apples. Food Qual. Prefer. 2017, 61, 55-62. [CrossRef]

(C) 2019 by the authors. Licensee MDPI, Basel, Switzerland. This article is an open access article distributed under the terms and conditions of the Creative Commons Attribution (CC BY) license (http:/ / creativecommons.org/licenses/by/4.0/). 